\title{
Valved stents for transapical pulmonary valve replacement
}

\author{
Christoph H. Huber, MD, ${ }^{a}$ Michel Hurni, MD, ${ }^{a}$ Victor Tsang, MD, ${ }^{b}$ and Ludwig K. von Segesser, MD ${ }^{a}$
}

Objectives: Pulmonary valve insufficiency remains a leading cause for reoperations in congenital cardiac surgery. The current percutaneous approach is limited by the size of the access vessel and variable right ventricular outflow tract morphology. This study assesses the feasibility of transapical pulmonary valve replacement based on a new valved stent construction concept.

Methods: A new valved stent design was implanted off-pump under continuous intracardiac echocardiographic and fluoroscopic guidance into the native right ventricular outflow tract in 8 pigs $(48.5 \pm 6.0 \mathrm{~kg})$ through the right ventricular apex, and device function was studied by using invasive and noninvasive measures.

Results: Procedural success was $100 \%$ at the first attempt. Procedural time was $75 \pm 15$ minutes. All devices were delivered at the target site with good acute valve function. No valved stents dislodged. No animal had significant regurgitation or paravalvular leaking on intracardiac echocardiographic analysis. All animals had a competent tricuspid valve and no signs of right ventricular dysfunction. The planimetric valve orifice was $2.85 \pm 0.32$ $\mathrm{cm}^{2}$. No damage to the pulmonary artery or structural defect of the valved stents was found at necropsy.

Conclusions: This study confirms the feasibility of direct access valve replacement through the transapical procedure for replacement of the pulmonary valve, as well as validity of the new valved stent design concept. The transapical procedure is targeting a broader patient pool, including the very young and the adult patient. The device design might not be restricted to failing conduits only and could allow for implantation in a larger patient population, including those with native right ventricular outflow tract configurations.

Earn CME credits at

http://cme.ctsnetjournals.org

Reoperative pulmonary valve replacement becomes necessary in 2 situations: (1) pulmonary valve regurgitation, generally after surgical transannular patch repair in patients with tetralogy of Fallot, ${ }^{1-3}$ and (2) dysfunction of the biologic valved conduit, establishing the continuity between the right ventricle and the pulmonary artery. ${ }^{4}$ Current practice consists of surgical pulmonary valve replacement or replacement of the failing conduit, respectively.

Several alternative strategies, particularly in the presence of dysfunction of the biologic valved conduit, have been considered within the last years, including new biologic valved conduits ${ }^{5-7}$ and endovascular procedures to delay the surgical replacement of the obstructed conduit ${ }^{8-12}$ and

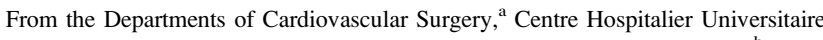
Vaudois (CHUV), Lausanne, Switzerland, and Cardio-Thoracic Surgery, ${ }^{\text {b }}$ Great Ormond Street Hospital for Children (GOSH) NHS Trust, London, United Kingdom.

Supported in part by the Swiss National Science Foundation grant 3200B0-113437, Bern, Switzerland. Materials for Valved Stent assembly were provided by Medtronic International, Tolochenaz, Switzerland.

Received for publication March 3, 2008; revisions received Aug 1, 2008; accepted for publication Sept 10, 2008.

Address for reprints: Christoph H. Huber, MD, Great Ormond Street Hospital, Cardio Thoracic Surgery, Great Ormond St, London WC1N 3JH, United Kingdom (E-mail: huberch@gmail.com).

J Thorac Cardiovasc Surg 2009;137:914-8

$0022-5223 / \$ 36.00$

Copyright (C) 2009 by The American Association for Thoracic Surgery doi: $10.1016 /$ j.jtcvs.2008.09.024
}

allow implantation of a larger valve to accommodate the patient's age and growth potential.

Endovascular stenting of stenosed right ventricular conduits is limited by the resulting pulmonary regurgitation and the subsequent right ventricular volume overload, resulting in increased incidence of sudden death, ventricular arrhythmias, and ventricular dysfunction. ${ }^{8,9}$

There is no doubt about the many advantages of valved stent implantation for both stenotic and dilated conduits. The currently used pulmonary valved stent device presents two limitations. The first relates to the maximum valve diameter of $22 \mathrm{~mm}$ resulting from the particular origin and processing of the harvested bovine jugular vein. The second particularity is that the device stent geometry only allows implantation in a small percentage of patients $(13 \%)$ because of the variable morphology of the aneurismal conduits. ${ }^{13,14}$

A further challenging limitation is the size mismatch between the venous access vessel and the introducer size. The $18 \mathrm{~F}$ introducer allows implantation only in older children. ${ }^{15}$

This study addresses the mentioned shortcomings by focusing on approaching the failing conduit by means of a direct access valve replacement strategy through the right ventricular apex in the so-called transapical procedure. A new device allowing perprocedural construction was designed and tested in vivo. Furthermore, the proposed valved stent concept was validated by random participants at 2 consecutive medical technology events in Switzerland. ${ }^{16}$

\section{MATERIALS AND METHODS}

Based on our previous experience with pulmonary valved stents, a second-generation device allowing so-called periprocedural construction, 


\section{Abbreviations and Acronyms \\ ICE = intracardiac echo \\ IVUS $=$ intravascular ultrasound \\ RVOT $=$ right ventricular outflow tract}

meaning building the device during the procedure instead of before, was implanted in 8 pigs $(48.5 \pm 6.0 \mathrm{~kg})$. Performing direct access valve replacement via the transapical procedure through a subxiphoid incision permitted for off-pump implantation.

\section{Valved Stent and Delivery Device Construction}

The valved stent is built from 2 components: a valved bovine jugular vein conduit (Contegra pulmonary valved conduit; Medtronic International Trading SARL, Tolochenaz, Switzerland) and a size-matched endoprosthetic graft (Valiant thoracic stent graft, Medtronic; Figure 1). The scaffold is constructed by shortening the endoprosthetic graft down to 2 segment lengths, including 2 rows of $Z$ stents. The valved conduit is then cut to approximate the stent graft length. The trimmed valve conduit is introduced into the stent graft, and 2 suture lines are started at each end to safely secure the 2-layer composite device.

The delivery device consists of a large $25 \mathrm{~F}$ endograft delivery system (XCelerant, Medtronic; Figure 2) to accommodate for the manually crimped and loaded valved stent. Delivery is performed by means of counterclockwise turning of the rotational handle or by using a quick-release mechanism, resulting in a pullback motion of the delivery sheath. A more detailed description of the device assembly has been reported previously. ${ }^{16}$

All devices (Figure 1) underwent in vitro testing before experimental in vivo implantation. Static leakage testing and dynamic pulsatile mock-loop assessment were performed. Real-time intravascular ultrasonography (12.5 $\mathrm{MHz}, 6 \mathrm{~F}$; Clearview; Boston Scientific Corp, Sunnyvale, Calif) was used to assess the correct functioning of the valved stent over an observation period of 30 minutes. Both tests have been described previously. ${ }^{17}$

\section{Surgical Access}

For tracheal intubation and mechanical ventilation, general anesthesia was induced with $22 \mathrm{mg} / \mathrm{kg}$ ketamine, $0.8 \mathrm{mg} / \mathrm{kg}$ atropine administered intramuscularly, and $15 \mathrm{mg} / \mathrm{kg}$ thiopental administered intravenously and maintained with $2.5 \%$ isoflurane. Continuous monitoring of electrocardiographic results, arterial pressure (from a catheter in the right carotid artery), central venous pressure, and oxygen saturation was performed. Additional intravenous access was gained through the superficial vein of the left ear.

After bilateral preparation of the carotid arteries and the jugular veins, a Swan-Ganz catheter for continuous cardiac output measurements was temporarily inserted through the right jugular vein, and a second intravenous line was placed in the left jugular vein. Then the arterial pressure line was inserted into the left carotid artery. Access for the intracardiac echocardiogram was obtained by exposing the proximal right femoral vein and inserting an $11 \mathrm{~F}$ introducer (B-Braun; Medical, Inc, Bethlehem, Pa).

Next, the endoscope was introduced into the right lower hemithorax to identify the preferred primary access for device insertion. Frequently, the location was subxiphoid to paraxiphoid. Then a 2- to 4-cm incision was performed. A xylocain $(1.5 \mathrm{mg} / \mathrm{kg})$ drip was started to minimize arrhythmias before mobilization of the pericardium. Two Teflon felt-reinforced Prolene (4-0) orthogonal U stitches were placed on the right ventricular apex. After heparinization (300 IU $/ \mathrm{kg}$ ), the $10 \mathrm{~F}$ intracardiac echo (ICE) probe with the bidirectional steering tip (Sequoia; operating frequencies, 4.0-10.0 MHz; 90-cm insertion length; Acuson Corp, Mountain View, Calif) was inserted to visualize the delivery process, as well as to measure the right ventricular outflow tract (RVOT) dimensions and the native

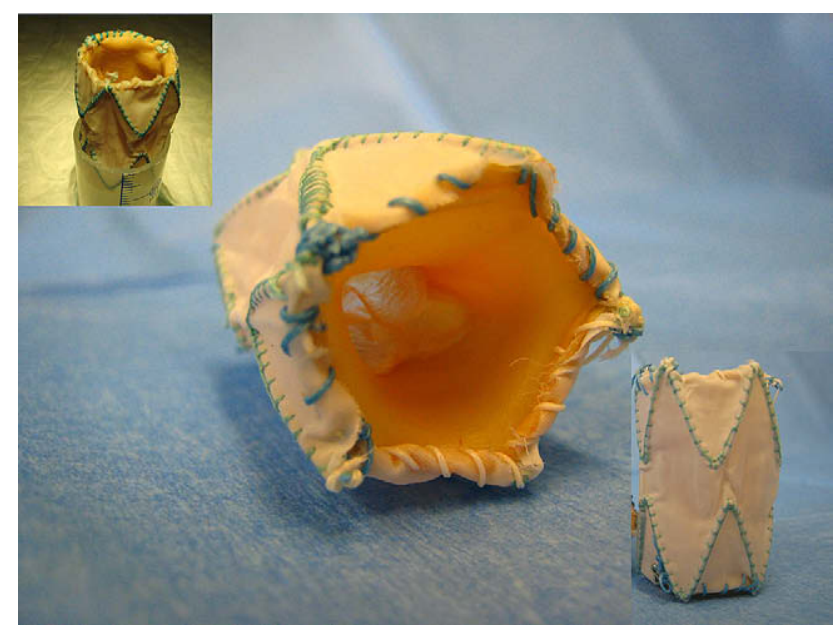

FIGURE 1. Late stage of the construction process is displayed (upper left corner). The finalized device displaying the Contegra valve placed in the Valiant endograft segment is shown. The front view of the device is shown in the right lower corner.

pulmonary valve, including annular diameter, valvular surface, and morphology of the pulmonary root.

\section{Off-Pump Pulmonary Valved Stent Implantation}

The valved stent was hand crimped onto the delivery system (Figure 2). Next, the prepared right ventricular apex was punctured, and an over-theneedle $8 \mathrm{~F}$ introducer system (Arrows, Reading, Pa) was inserted. Under fluoroscopic guidance, a soft-tip 0.035 -inch guide wire was first advanced into the right pulmonary artery and then transcatheter exchanged for an ultrastiff Back-up Meier wire (0.035 inches, $185 \mathrm{~cm}$; Boston Scientific, Medi-tech, Watertown, Mass; Figure 3). Then the monorail wire-guided disposable intravascular ultrasound (IVUS) $6 \mathrm{~F}$ catheter transducer (Sonicath Ultra 6, 12.5-MHz Imaging Catheter; Medi-tech) providing a cross-sectional view with $80 \mathrm{~mm}$ of diameter was inserted. Simultaneous tracking of the IVUS probe with fluoroscopy allowed for identification and marking of the desired landing zone. Two radio-opaque markers were placed on the body surface ${ }^{18,19}$ to temporarily define the target zone, one at the

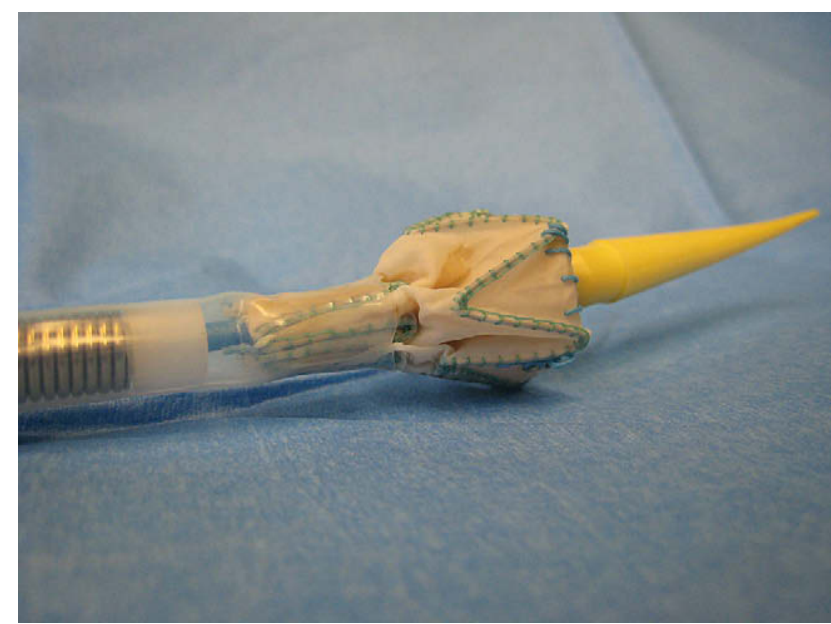

FIGURE 2. The valved stent manually crimped and partially loaded into the $25 \mathrm{~F}$ Valiant delivery system. 

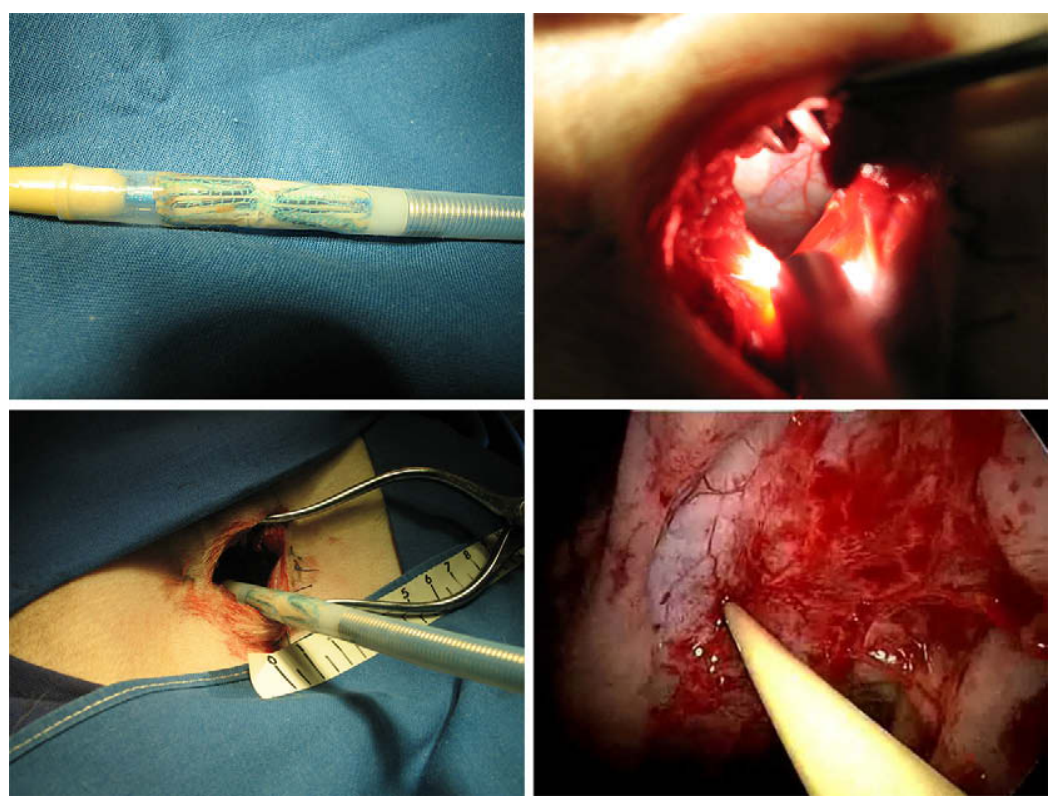

FIGURE 3. Four views of the implantation procedure (from top left to bottom right): device loaded onto the delivery system; endoscopic assessment of the ideal transapical procedure access location; 2- to 4-cm paraxiphoid or subxiphoid incision; insertion of the delivery system tip into the right ventricular apex.

fluoroscopic level of the pulmonary annulus and the second at the level of the pulmonary bifurcation.

\section{Periprocedural Valved Stent Position Assessment With ICE and Fluoroscopy}

The IVUS probe and the $8 \mathrm{~F}$ introducer were removed. The loaded and flushed valved stent delivery system was inserted over the guide wire during fluoroscopic and simultaneous ICE guidance. After the fluoroscopic and ultrasonographic target sites were congruent, the valved stent was deployed orthotopically over the native valves in a 2 -step procedure. First the distal end and then, if the location stayed unchanged, the proximal end was released. The valved stent's initial landing site was chosen slightly above the prior identified target site to accommodate for minor position corrections. Therefore after opening the first row of $\mathrm{Z}$ stents, the whole device could be pulled back until the landing and target site matched the fluoroscopic and ultrasonographic assessments. No contrast medium was used throughout the procedure.

\section{Outcome Assessment}

After device deployment, the $6 \mathrm{~F}$ IVUS transducer was reintroduced through the valve. Further measures were taken with the Doppler-supporting $8 \mathrm{~F}$ ICE probe positioned in the right atrium. Finally, a $5 \mathrm{~F}$ catheter (Cook, Inc, Bloomington, Ind) was inserted over the guide wire to assess the transvalvular gradient, the $7.5 \mathrm{~F}$ Swan-Ganz catheter was advanced into the pulmonary artery, and cardiac output was measured. The observation period was 6 hours.

Acute in vivo assessment included the length and diameter of the pulmonary trunk before implantation, device position, leaflet motion, planimetric valve orifice, transvalvular gradient, regurgitation, and paravalvular leaking. At the end of the experiments, the animals were killed, and macroscopic analysis was performed at necropsy.

The institutional Committee on Animal Research approved the protocol. All animals received human care in compliance with the "Principles of laboratory animals" formulated by the National Society of Medical Research and the "Guide for the care and use of laboratory animals" prepared by the Institute of Laboratory Animal Resources and published by the National
Institutes of Health (National Institutes of Health publication no. 85-23, revised 1985). All data are expressed as the mean \pm standard deviation.

\section{RESULTS}

Procedural success was $100 \%$ ( $8 / 8$ pigs) at the first attempt. Mean procedure time, including device construction, was $75 \pm 15$ minutes. All valved stents were delivered at the target site over the native pulmonary valve with good acute valve function. No valved stents dislodged into either the right ventricle or the pulmonary trunk.

No significant hemodynamic differences between mean carotid arterial pressure, oxygen saturation, or central venous pressure before and after implantation were identified $\left(P_{1}=.45, P_{2}=.57\right.$, and $\left.P_{3}=.64\right)$ during implantation; in 2 cases temporary supraventricular tachycardia was experienced. Continuous cardiac output remained stable throughout the procedure at $4.20 \pm 1.35 \mathrm{~L} / \mathrm{min}$.

The peak-to-peak transvalvular pressure gradient ranged from $5.7 \pm 3.1 \mathrm{~mm} \mathrm{Hg}$ (range, 4.2-10.4 $\mathrm{mm} \mathrm{Hg}$ ) at Doppler echocardiographic analysis and $4.9 \pm 2.4 \mathrm{~mm} \mathrm{Hg}$ (range, 1-7 mm Hg) on invasive measurements.

The native pulmonary artery diameter at the valve level was $19.4 \pm 1.6 \mathrm{~mm}$ (approximately $2.9 \mathrm{~cm}^{2}$ ).

The length of the pulmonary trunk measured $4.2 \pm 0.4$ $\mathrm{cm}$. No animal had significant regurgitation or paravalvular leak after implantation on intracardiac echocardiographic analysis. The IVUS demonstrated the complete opening and closing of the valve, with a planimetric valve orifice of $2.85 \pm 0.32 \mathrm{~cm}^{2}$.

No damage to the pulmonary artery or structural defects of the valved stents was found at necropsy. Macroscopic analysis 
confirmed the adequate positioning within the defined landing zone. Neither thrombus formation nor leaflet damage or structural device failure were identified on gross visual examination.

\section{DISCUSSION}

Transcatheter pulmonary valve replacement harbors many benefits, even more so in the setting of reoperation for dilated conduits or progressive pulmonary incompetence after a nonvalved RVOT enlargement strategy. The purpose of the valve replacement is to restore physiologic hemodynamic conditions and to prevent or reduce the incidence of sudden death, arrhythmias, and right ventricular dysfunction $^{1,2,20}$ with the lowest possible surgical risk.

Reoperations become necessary in at least $10 \%$ of all patients after primary correction of tetralogy of Fallot. Indications typically are RVOT enlargement and progressive pulmonary regurgitation after patch repair. ${ }^{3}$ Perioperative and postoperative mortality of surgical pulmonary valve replacement is close to zero. ${ }^{2}$ Postoperative results are excellent, with marked clinical improvements due to right ventricular end-diastolic volume regression.

Transvenous remote insertion for percutaneous pulmonary valve replacement remains restricted to a small percentage ${ }^{13}$ of patients. The Melody transcatheter pulmonary valve (Medtronic B.V., Heerlen, The Netherlands) is limited 2-fold, first by a very defined morphology of the failing right ventricular conduit and second by the size of the access vessel, allowing insertion of the $18 \mathrm{~F}$ delivery system only in larger femoral veins or children weighing more than $25 \mathrm{~kg}$, respectively.

Our experimental study presents an alternative off-pump approach. Direct access valve replacement through the transapical procedure through the right ventricular apex allows for "larger" device implantation, regardless of the patient's age and vascular tree, allowing implantation also in adult patients. ${ }^{3}$ Increased device dimensions rationalize implantation also in patients with worsening dilatation of the RVOT after previous patch enlargement. In a previous porcine study with heavier adult animals, the mean external device diameter was measured at $26.3 \pm 0.7 \mathrm{~mm}^{21}$

The present study focused on reproducing conditions of a pediatric patient population. Because the device is self-expanding, it might be able to adapt to the growing pulmonary artery, and further device dilatation might be supplemented by balloon dilatation. Furthermore, the device design might make it more suitable for native RVOT implantation.

Valved stent device construction is believed to be simple and safe enough when handled by trained and experienced personnel. The perprocedural patient-adapted construction concept was further validated in 2 consecutive medical technology meetings with more than 70 random participants and a $92 \%$ successful device construction and implantation. ${ }^{16}$

Biotolerance, functionality, and approval of both components are expected to face no major resistance because the bovine jugular vein conduit, as well as the endograft, are ap- proved for clinical use, the first for RVOT reconstruction in congenital patients with failing conduits and the second in endoluminal grafting of aortic aneurysm. Diverse studies have shown good midterm outcomes of the bovine jugular graft in well-selected patients. ${ }^{22-25}$ The valve has also shown its validity in percutaneous procedures in more than 300 patients within the commercially available Melody device (Bonhoeffer P, personal communication). Nevertheless, long-term results will remain a matter of debate until further studies are performed. Durability of the valve might be altered by the implantation within the prosthetic graft, but only chronic and future clinical implants can clarify those concerns. The valvular device component might be changed to a commercial stentless tissue valve or to a homograft implanted into the self-expanding endograft to accommodate larger native RVOTs, but again, follow-up animal studies will have to show the validity of the modified device.

A similar device, the Shelhigh injectable pulmonic valve (Shelhigh, Inc, Union, NJ), ${ }^{26}$ showed very promising results $^{27,28}$ and confirmed the clinical feasibility of intraoperative implantation for pulmonary regurgitation. Six patients (9-27 years of age) with primary total correction of tetralogy of Fallot at $4.2 \pm 4.0$ years of age received the injectable porcine pulmonary valved stent. No major adverse event was reported, and all except one implantation was successful, with encouraging 6- to 12-month follow-up data.

The former device required additional fixation by using a few surgical stitches. In the present study we did not experience either dislodgement or migration, but of course this very justified concern remains a key element for successful outcomes. This complication might be prevented by using a carrier graft with enforced anchoring capacity, such as hooks or barbs, to help improve anchoring in native, dilated, or noncalcified RVOTs. This represents a new device concept the authors are currently investigating.

The presented preliminary experimental data are limited to acute experimental observations but do harbor essential conditions for clinical implementation in the near future. Of course, the concept requires further validation in chronic studies.

\section{CONCLUSIONS}

The off-bypass transapical implantation of a self-expanding valved stent is feasible over the native pulmonary valve. Intravascular and intracardiac echocardiography combined with fluoroscopy makes implantation and evaluation easy and reproducible; there is no need for angiography. The off-bypass transapical approach allows for valved stent implantation of any size, including the adult size, with adequate hemodynamic functioning regardless of the size of the access vessel.

\section{References}

1. Warner KB, Anderson JE, Fulton DR, Payne DD, Geggel RL, Marx GR. Restoration of the pulmonary valve reduces right ventricular volume overload after previous repair of tetralogy of Fallot. Circulation. 1993;88(suppl II):189-97. 
2. Therrien J, Siu SC, McLaughlin PR, Liu PP, Williams WG, Webb GD. Pulmonary valve replacement in adults after repair of tetralogy of Fallot: are we operating too late? J Am Coll Cardiol. 2000;36:1670-5.

3. Oechslin EN, Harrison DA, Harris L, Downar E, Webb GD, Siu SS, et al. Reoperation in adult with repair of tetralogy of Fallot: indications and outcomes. J Thorac Cardiovasc Surg. 1999;118:245-51.

4. Stark J, Bull C, Stajevic M, Jothi M, Elliott M, de Leval MR. Fate of subpulmonary homograft conduits: determinants of late homograft failure. J Thorac Cardiovasc Surg. 1998;115:506-16.

5. Hoerstrup SP, Kadner A, Breymann C, Maurus CF, Guenter CI, Sodian R, et al. Living, autologous pulmonary artery conduits tissue engineered from human umbilical cord cells. Ann Thorac Surg. 2002;74:46-52.

6. Corno AF, Hurni M, Griffin H, Galal OM, Payot M, Sekarski N, et al. Bovine jugular vein as right ventricle-to-pulmonary artery valved conduit. J Heart Valve Dis. 2002;11:242-7.

7. Stock UA, Nagashima M, Khalil PN, Nollert GD, Herden T, Sperling JS, et al. Tissue-engineered valved conduits the pulmonary circulation. J Thorac Cardiovasc Surg. 2000;119:732-40.

8. Powell AJ, Lock JE, Keane JF, Perry SB. Prolongation of RV-PA conduit life span by percutaneous stent implantation. Intermediate-term results. Circulation. 1995;92:282-8.

9. Saliba Z, Bonhoeffer P, Aggoun Y, Iserin L, Butera G, Bonnet D, et al. Treatment of obstruction of prosthetic conduits by percutaneous implantation of stents. Arch Mal Coeur Vaiss. 1999;92:591-6.

10. Bonhoeffer P, Boudjemline Y, Saliba Z, Hausse AO, Aggoun Y, Bonnet D, et al. Transcatheter implantation of a bovine valve in pulmonary position. A lamb study. Circulation. 2000;102:813-6.

11. Bonhoeffer P, Boudjemline Y, Saliba Z, Merckx J, Aggoun Y, Bonnet D, et al. Percutaneous replacement of pulmonary valve in a right-ventricle to pulmonary-artery prosthetic conduit with valve dysfunction. Lancet. 2000;356:1403-5.

12. Pedra CA, Justino H, Nykanen DG, VanArsdell G, Coles JG, Williams WG, et al. Percutaneous stent implantation to stenotic bioprosthetic valves in the pulmonary position. J Thorac Cardiovasc Surg. 2002;124:82-7.

13. Schievano S, Coats L, Migliavacca F, Norman W, Frigiola A, Deanfield J, et al. Variations in right ventricular outflow tract morphology following repair of congenital heart disease: implications for percutaneous pulmonary valve implantation. J Cardiovasc Magn Reson. 2007;9:687-95.

14. Nordmeyer J, Coats L, Bonhoeffer P. Current experience with percutaneous pulmonary valve implantation. Semin Thorac Cardiovasc Surg. 2006;18:122-5.

15. Bonhoeffer P, Boudjemline Y, Qureshi SA, Le Bidois J, Iserin L, Acar P, et al. Percutaneous insertion of the pulmonary valve. J Am Coll Cardiol. 2002;39:1664-9.
16. Huber ChH, Marty B, von Segesser LK. Acceptance and introduction of disruptive technologies-simple steps to build a fully functional pulmonary valved stent. Interact Cardiovasc Thorac Surg. 2007;6:430-2.

17. Ma L, Tozzi P, Huber Ch, Taub S, Gerelle G, von Segesser LK. Setup of a new in vitro mock loop system and testing of a valved stent in mitral position. Swiss Perfusion. 2007;20:4-7.

18. von Segesser LK, Marty B, Ruchat P, Bogen M, Gallino A. Routine use of intravascular ultrasound for endovascular aneurysm repair: angiography is not necessary. Eur J Vasc Endovasc Surg. 2002;23:537-42.

19. Huber CH, Nasratulla M, Augstburger M, von Segesser LK. New tools for new goals: ultrasound navigation through the heart for off pump aortic valved stent implantation. J Endovasc Ther. 2004;11:503-10.

20. Discigil B, Dearani JA, Puga FJ, Schaff HV, Hagler DJ, Warnes CA, et al. Late pulmonary valve replacement after repair of tetralogy of Fallot. J Thorac Cardiovasc Surg. 2001;121:344-51.

21. Zhou JQ, Corno AF, Huber CH, Tozzi P, von Segesser LK. Self-expandable valved stent of large size: off-bypass implantation in pulmonary position. Eur $J$ Cardiothorac Surg. 2003;24:212-6.

22. Rastan AJ, Walther T, Daehnert I, Hambsch J, Mohr FW, Janousek J, et al. Bovine jugular vein conduit for right ventricular outflow tract reconstruction: evaluation of risk factors for mid-term outcome. Ann Thorac Surg. 2006;82:1308-15.

23. Brown JW, Ruzmetov M, Rodefeld MD, Vijay P, Darragh RK. Valved bovine jugular vein conduits for right ventricular outflow tract reconstruction in children: an attractive alternative to pulmonary homograft. Ann Thorac Surg. 2006;82: 909-16.

24. Corno AF, Qanadli SD, Sekarski N, Artemisia S, Hurni M, Tozzi P, et al. Bovine valved xenograft in pulmonary position: medium-term follow-up with excellent hemodynamics and freedom from calcification. Ann Thorac Surg. 2004;78: 1382-8.

25. Breymann T, Boethig D, Goerg R, Thies WR. The Contegra bovine valved jugular vein conduit for pediatric RVOT reconstruction: 4 years experience with 108 patients. J Card Surg. 2004;19:426-31.

26. US Food and Drug Administration. FDA request recall of all Shelhigh Medical Devices. Washington (DC): US Food and Drug Administration; 2007. Publication no. P07-78.

27. Berdat PA, Schönhoff F, Pavlovic M, Pfammatter JP, Carrel T. Cardiology in the Young. Abstract book 2006;O-39:15.

28. Schreiber C, Hörer J, Vogt M, Fratz S, Kunze M, Galm C, et al. A new treatment option for pulmonary valve insufficiency: first experiences with implantation of a self-expanding stented valve without use of cardiopulmonary bypass. Eur $J$ Cardiothorac Surg. 2007;31:26-30. 